\title{
Article \\ A Comprehensive Optimization of Ultrasound-Assisted Extraction for Lycopene Recovery from Tomato Waste and Encapsulation by Spray Drying
}

\author{
Junyang Li, Margherita Pettinato*(D), Alessandro Alberto Casazza (iD) and Patrizia Perego (D)
}

Citation: Li, J.; Pettinato, M.; Casazza, A.A.; Perego, P. A Comprehensive Optimization of Ultrasound-Assisted Extraction for Lycopene Recovery from Tomato Waste and Encapsulation by Spray Drying. Processes 2022, 10, 308. https:// doi.org/10.3390/pr10020308

Academic Editor: Pavel Mokrejš

Received: 12 January 2022

Accepted: 3 February 2022

Published: 4 February 2022

Publisher's Note: MDPI stays neutral with regard to jurisdictional claims in published maps and institutional affiliations.

Copyright: (C) 2022 by the authors. Licensee MDPI, Basel, Switzerland. This article is an open access article distributed under the terms and conditions of the Creative Commons Attribution (CC BY) license (https:// creativecommons.org/licenses/by/ $4.0 /$ )
Department of Civil Chemical and Environmental Engineering, University of Genoa, Via Opera Pia, 15, 16145 Genoa, Italy; junyang.li@edu.unige.it (J.L.); alessandro.casazza@unige.it (A.A.C.); p.perego@unige.it (P.P.) * Correspondence: margherita.pettinato@edu.unige.it

\begin{abstract}
This study aimed to extract bioactive compounds from tomato waste through ultrasoundassisted extraction (UAE), using ethanol as solvent. Process optimization was carried out by a central composite design of 33 runs for response surface modelling, simultaneously analyzing the effect of temperature $(T)$, time $(t)$, volume $(V)$, liquid-to-solid ratio $(L / S)$, amplitude $(A)$, the pulser duration (on), and their interaction. The best conditions found by the desirability method $\left(T=65^{\circ} \mathrm{C}, t=20 \mathrm{~min}\right.$, $L / S=72 \mathrm{~mL} / \mathrm{g}, A=65 \%$, on $=33 \mathrm{~s}, V=90 \mathrm{~mL}$ ) were experimentally verified, leading to the production of an extract with interesting properties (total carotenoids of $1408 \pm 14 \mu \mathrm{g}_{\text {lycopene equivalents }} / \mathrm{g}$, lycopene yield of $1536 \pm 53 \mu \mathrm{g} / \mathrm{g}, 36.1 \pm 0.9 \mu \mathrm{g}_{\text {trolox equivalents }} / \mathrm{g}$ as antiradical power). Due to the instability of lycopene, the extract encapsulation by spray drying was undertaken using inulin and maltodextrins as coating agents. The evaluation of wall material composition provided high product recovery $(73 \%)$, a high content of encapsulated compared to superficial lycopene (15.3 \pm 2.9 and $0.30 \pm 0.02 \mu \mathrm{g} / \mathrm{g}$ ), and a product with good water solubility. The novelty of this work concerned the simultaneous study of the effect and interdependences of the UAE parameters, and the use of inulin to enhance the properties of microparticles.
\end{abstract}

Keywords: response surface modeling; green processes; waste valorization; antiradical power; carotenoids; inulin; spray drying

\section{Introduction}

\subsection{Lycopene}

Lycopene belongs to the carotenoid family exhibiting brilliant colors from yellow to red, which makes it an interesting natural pigment [1]. In addition, carotenoids have excellent health properties due to their ability to quench singlet oxygen and free radicals. Their antioxidant activity explains the efforts of researchers and industries to find new ways to exploit such compounds for the development of new functional food and beverage [2], pharmaceutical, and cosmetic products [3]. The chemical structure of lycopene is responsible for its antioxidant properties, but also for its hydrophobic nature, being soluble in tissues, milk and organic solvents, such as benzene, chloroform or methylene chloride [3]. Lycopene can be produced synthetically, or recovered from natural sources, including agri-food industry by-products such as tomato peels. To maximize the recovery of these functional ingredients and to reduce the process environmental impacts, green solvents and pressure- [1,4], microwave- [5], and ultrasound-assisted processes [6-8] have been employed.

\subsection{Ultrasound-Assisted Extraction}

The mechanical effect of ultrasounds can be efficiently exploited to separate active compounds from tomato tissue. Indeed, they are able to provide a greater penetration of a given solvent into the cellular materials, disrupting the biological cell walls to facilitate 
the release of contents [9]. Ultrasound-assisted extraction (UAE) is based on the cavitation phenomenon, which firstly consists in the formation of bubbles when the negative pressure, caused by ultrasonic wave, leads to liquid breakdowns and voids; secondly, the cavitation bubbles expand under high ultrasound intensity, leading to a violent collapse after a few cycles (transient cavitation) of compression $[10,11]$. A large amount of energy is released by bubble implosions, causing significant changes in the local temperature and pressure, liquid circulation, and turbulence. The consequence of these effects is a significant increase in mass transfer rate. Extreme local conditions allow the inducement of other mechanisms such as fragmentation, increased absorption, localized erosion, shear force, pore formation, and swelling of the plant cell matrix. These mechanisms are able to provide a larger surface area, increased accessibility of the solvent, and destruction of the cell walls [12]. The phenomena involved in UAE can improve extraction yields and accelerate extraction rates, compared with conventional extraction, resulting in short extraction times and higher productivity [7]. UAE may be considered a green and sustainable process [13], allowing several advantages including versatility, simplicity, safety, rapidity, eco-friendliness and cost-effectiveness. The process intensification allowed by ultrasounds application is able to provide high extraction yields using green (and safer) solvents, compared with conventional solid-liquid extraction, which often requires organic and toxic solvents to achieve good performance. In addition, the better performance of UAE compared with conventional techniques allows the use of lower solvent volumes, which implies, at an industrial level, smaller and more controllable equipment and the reduction of the magnitude of damages due to potential accidents [14]. The selection of solvent plays an important role in UAE, since solvent features such as vapor pressure, surface tension, density, and viscosity influence the cavitation phenomenon. To further reduce environmental impact, the replacement of the conventional organic solvents with more eco-friendly ones has often been proposed in the literature $[6,8,12]$. Ethanol is a sustainable and green solvent, as it can be produced by fermenting renewable sources [15], and its molecular structure allows for the dissolving of both polar, hydrophilic, and nonpolar, hydrophobic compounds; thus, it can be used for the recovery of lycopene from agro-industrial waste. The development of sustainable extraction processes based on ultrasounds requires the optimization of the process parameters to propose efficient solutions to the market. Temperature, pressure, frequency, pulsation, amplitude, volume, and liquid-to solid ratio can strongly influence the success of the extraction process [12]. Furthermore, cavitation is also able to generate solvent radicals, which can react with solutes to induce oxidation reactions and degradation [10]; thus, the operating conditions adopted need to be carefully tuned. For these reasons, this work aims to provide the optimization of UAE by investigating the effects of temperature, time, liquid-to solid ratio, on/off pulsed ratio, amplitude, and volume on the recovery of lycopene from tomato industry waste. The novelty of this work is related to the attempt to simultaneously study the effect and interdependences of process parameters by means of response surface modelling. Lycopene extraction yield, total carotenoids, and antiradical power of the extract were selected as response variables. Albeit some of these variables were evaluated in several papers [4-6,8], to the best of our knowledge the simultaneous investigation of all the main operating conditions to maximize the extraction performances, including the total volume of the extraction system, have not been previously examined. In addition, the microencapsulation of the extract obtained in the best conditions was evaluated.

\subsection{Spray Drying}

Spray drying is a low-cost industrial consolidated technique, providing dry and goodquality products [16]. The process is carried out by evaluating the composition of the wall material, composed of maltodextrins and inulin. Maltodextrins are commonly used in the spray-drying encapsulation process due to their high water solubility, low-cost, mild flavor, and good encapsulation performances [17]. Several health benefits are related to the consumption of the dietary fiber inulin, which facilitates intestinal regularity and prevents the development of tumors. It also seems to reduce total and LDL cholesterol 
absorption and improve calcium absorption in the intestine [18]. This technique protects and increases the shelf-life of many active substances that are chemically fragile and unstable, and modulates their properties according to the coating agent selection [16]. This study represents an attempt to combine the health properties of tomato antioxidants and inulin in a dry formulation, enhancing lycopene water solubility.

\section{Materials and Methods}

\subsection{Chemicals and Sample Preparation}

Ethanol (analytical grade, Sigma Aldrich, St. Louis, MO, USA); 2,2'-azino-bis (3-ethylbenzothiazoline-6-sulphonic acid) diammonium salt (Sigma Aldrich, Milan, Italy); potassium persulfate, iso-propanol, acetonitrile, methanol (Carlo Erba, Cornaredo, Italy), all-trans-lycopene and the standards (Sigma Aldrich, Milan, Italy) employed in this study were of analytical grade and used without further purification. The water was obtained with a Milli-Q system (Merck-Millipore, Darmstadt, Germany). Tomato peels and seeds were kindly provided by a producer of tomato sauce in northern Italy. The tomato waste resulting from this process were partially stored at $-20{ }^{\circ} \mathrm{C}$ for characterization of the biomass, and partially dried at $60^{\circ} \mathrm{C}$ up to constant weight for extraction experiments.

\subsection{Characterization of Tomato Waste}

The moisture content of fresh tomato waste was obtained by drying approximately $3.0 \mathrm{~g}$ of fresh sample at $110^{\circ} \mathrm{C}$ until a constant weight was observed. Moisture was reported as a percentage with respect the initial mass of wet sample.

The tomato waste ashes were obtained by treating approximately $0.5 \mathrm{~g}$ of the dried sample at $650{ }^{\circ} \mathrm{C}$ for $4 \mathrm{~h}$. Tests were performed in triplicate and reported as mean value \pm standard deviation of the percentage of ashes with respect to the initial dried sample.

The water activity of the dried tomato waste was detected by HygroPalm-HP23-AW-A (Rotronic, Crawley, UK).

Particle size distribution (PSD) of dried tomato waste was performed by sieving. Approximately $40 \mathrm{~g}$ of the sample was treated for 15 min using a vibratory sieve shaker machine (Giuliani, Tecnologie, Torino, Italy) and a series of sieves (openings: 3.327, 2.794, $1.981,1.651,1.168,1.000,0.840,0.701,0.500,0.420,0.355,0.250 \mathrm{~mm}$ ). The masses of each fraction $\left(m_{j}\right)$ were weighed, and the respective range of diameters was labelled by the arithmetic mean of the two sieve openings $\left(d_{j}\right)$. The cumulative function of the undersize up to a diameter value $d_{k}\left(F\left(d_{k}\right)\right)$ was built according to Equation (1):

$$
F\left(d_{k}\right)=\sum_{j=1}^{j=k} \chi_{j}
$$

where $\chi_{j}$ are the mass fractions related to the single diameter interval $d_{j}$. The mean value of the PSD was determined graphically, as the area under the curve of the cumulative fraction $(F(d))$ versus $d$, with respect to the $F(d)$ axis [19], according to the discretized form of Equation (2).

$$
\overline{g(d)}=\int_{0}^{1} g(d) d F=\sum_{k} \frac{1}{2} \cdot\left[g\left(d_{k}\right)+g\left(d_{k-1}\right)\right] \cdot\left[F\left(d_{k}\right)-F\left(d_{k-1}\right)\right]
$$

Tests were carried out in triplicate and reported as mean value \pm standard deviation.

\subsection{Ultrasound-Assisted Extraction}

Lycopene extraction from tomato waste was carried out by UAE. This method allows the extraction of bioactive compounds in very short time, at a low temperature, with lower energy and solvent requirement, and it is particularly suitable for the recovery of the thermosensitive bioactive compounds [12]. The apparatus used was made by an ultrasonic probe (Sonicator Vibra cell 75115, 700 W, Bioblock Scientific Co., Strasbourg, 
France) equipped with a tip of $13 \mathrm{~mm}$, working at $20 \mathrm{kHz}$ of frequency. The probe was directly submerged into a $150 \mathrm{~mL}$ beaker, which hosted dried tomato waste and the solvent (ethanol). Temperature was detected by a thermocouple and controlled by a thermostatic bath. After the extraction, the liquid was separated from the exhausted solid by centrifugation (6036 $\times g$ for $10 \mathrm{~min}$ ) (MF-20-R, Alliance Bio Expertise, Guipry, France) and filtration $(0.45 \mu \mathrm{m}$ filter $)$ and stored at $-20{ }^{\circ} \mathrm{C}$ for further analyses.

\subsubsection{Experimental Design}

Response Surface Methodology (RSM) [20] was used to investigate the effect of the ultrasound-assisted extraction parameters on the extract bioactive content. A Central Composite Design (CCD) was employed as the experimental design. The CCD consisted of factorial points, each having two levels $( \pm 1)$, a set of central points (level 0 ), and a set of star points, where experimental runs were in the same level as the centre points, except for one factor, whose distance from the centre of the design space was $\pm \alpha$ where $|\alpha| \geq 1$. The setting of the $\alpha$ value (1.565) and the number of trials at the centre of the domain influence the accuracy of the estimation [21].

The factors investigated included extraction temperature $\left(35-65^{\circ} \mathrm{C}\right)$, time $(20-50 \mathrm{~min})$, volume of the extraction system $(45-90 \mathrm{~mL})$, liquid-to-solid ratio $(27-80 \mathrm{~mL} / \mathrm{g})$, amplitude (30-65\%) and on/off pulsed ratio (30-70 s). The last was defined as the time of applied ultrasounds in a cycle where the relaxation time (ultrasounds were not applied) was fixed to $30 \mathrm{~s}$. Ranges of variation of each input variable were coded according to Equation (3), in such a way that they could vary from -1 to 1 :

$$
\mathrm{X}_{\mathrm{i}}=\frac{\left(\varphi_{\mathrm{i}}-\varphi_{\min }\right)}{\Delta \varphi / 2}-1
$$

where $X_{i}$ is the input variable, $\varphi_{i}, \varphi_{\min }$ and $\Delta \varphi$ are the actual variable value, the minimum variable value and variable range, in original units.

The experimental plan consisting of 33 experiments was used to optimize the content of active substances in the extract.

The individual and interaction effects of independent variables $\left(X_{j}\right)$ on the generic response $(Y)$ were mathematically fitted through a second order polynomial (Equation (4)):

$$
Y=\beta_{0}+\sum_{j=1}^{k} \beta_{j} X_{j}+\sum_{j=1}^{k} \beta_{j j} X_{j}^{2}+\sum_{j=1}^{k} \sum_{i=1}^{k} \beta_{i j} X_{i} X_{j}
$$

where $\beta_{0}$ is a constant and $\beta_{\mathrm{j}}, \beta_{\mathrm{jj}}$ and $\beta_{\mathrm{ij}}$ are the coefficients of the terms of the equation. The model adequacy was determined by means of the analysis of variance (ANOVA) using the Design Expert Software (Stat-Ease, Inc., Minneapolis, MN, USA).

The influence of the process operating conditions was evaluated on total carotenoid yield, lycopene yield, and antiradical power of the extract, which were selected as the response variables.

\subsubsection{Total Carotenoid Yield}

Total carotenoids were determined by UV-vis spectrophotometer (model Lambda 25, Perkin Elmer, Wellesley, MA, USA), and triplicate analyses were carried out on samples of obtained extracts, whose absorbance (ABS) was read at a wavelength of $470 \mathrm{~nm}$.

The concentration of total carotenoids was calculated using the calibration curve $\left(R^{2}=0.986\right)$, obtained from the standard solutions of all-trans-lycopene $(C=0.001-0.01 \mathrm{mg} / \mathrm{mL})$ reported in Equation (5).

$$
\mathrm{ABS}_{470 \mathrm{~nm}}=85.547 \times \mathrm{C}
$$


Total carotenoid yield (TC) was obtained by the Equation (6) as milligrams of lycopene equivalents (LE) per gram of dried biomass (DB):

$$
\mathrm{TC}\left(\frac{\mathrm{mg}_{\mathrm{LE}}}{\mathrm{g}}\right)=\frac{\mathrm{C} \times \mathrm{V} \times \mathrm{D}}{\mathrm{m}_{\mathrm{DB}}}
$$

where $\mathrm{V}$ is the volume of the solvent used for the extraction $(\mathrm{mL}), \mathrm{D}$ is the sample dilution factor (-) and $\mathrm{m}_{\mathrm{DB}}$ is the mass of dried tomato seeds and peels used for the extraction $(\mathrm{g})$.

\subsubsection{Lycopene Yield}

The method reported by Anguelova et al. [22] was applied for the investigation of lycopene in the extracts, with some modifications. The analyses were carried out using a High-Performance Liquid Chromatographer (Agilent 1100 series, Palo Alto, CA, USA), equipped with a C18 $(5 \mu \mathrm{m}, 4.6 \times 250 \mathrm{~mm})$ reversed phase column (Vydac, Hesperia, CA, USA), and a diode array detector (DAD). Before the analysis, samples were filtered through a $0.22 \mu \mathrm{m}$ membrane filter, then injected samples $(100 \mu \mathrm{L}$, without dilution) were detected at $470 \mathrm{~nm}$. An isocratic mobile phase (flow rate $=1 \mathrm{~mL} / \mathrm{min}$ ) of acetonitrile $(44 \% v / v)$, methanol $(54 \% v / v)$, and isopropanol $(2 \% v / v)$ was used. Lycopene content in the sample was calculated by peak area integration (A, mAU) and according to the calibration curve $\left(R^{2}=0.982\right)$, obtained from the standard solution of all-trans-lycopene $(\mathrm{C}=100-2700 \mu \mathrm{g} / \mathrm{mL})$, reported in Equation (7):

$$
\mathrm{A}=131.47 \times \mathrm{C}
$$

Lycopene yield (LY) was given through Equation (8), where V is the volume of the solvent used for the extraction $(\mathrm{mL})$ and $\mathrm{m}_{\mathrm{DB}}$ is the mass of dried tomato seeds and peels used for the extraction $(\mathrm{g})$ :

$$
\mathrm{LY}\left(\frac{\mu \mathrm{g}}{\mathrm{g}}\right)=\frac{\mathrm{C} \times \mathrm{V}}{\mathrm{m}_{\mathrm{DB}}}
$$

\subsubsection{Antiradical Power}

The ability of extracts to scavenge free radicals was evaluated by $\mathrm{ABTS}^{\bullet+}\left(2,2^{\prime}\right.$-azinobis (3-ethylbenzothiazolin-6-sulfonic acid)) assay [23]. Working solution of $7 \mathrm{mM} \mathrm{ABTS}{ }^{\bullet+}$ was prepared by adding $0.0959 \mathrm{~g}$ of 2,2'-azino-bis (3-ethylbenzothiazoline-6-sulphonic acid) diammonium salt in deionized water up to a final volume of $25 \mathrm{~mL}$ and $440 \mu \mathrm{L}$ of $140 \mathrm{mM}$ potassium persulfate solution. After $16 \mathrm{~h}$ of reaction under dark conditions, the working solution was used to assess extract antiradical power. Then, $50 \mu \mathrm{L}$ of properly diluted sample of the extract was added to $1 \mathrm{~mL}$ of $\mathrm{ABTS}^{\bullet+}$ working solution, and its absorbance was read after $2 \mathrm{~min}$ at $734 \mathrm{~nm}$ by a UV-vis spectrophotometer (model Lambda 25, Perkin Elmer, Wellesley, MA, USA). Antiradical power $(A R P)$ was expressed as micrograms of trolox equivalents (TE) per $\mathrm{kg}$ of dried biomass (DB), through the calibration curve reported by Aliakbarian et al. [24].

\subsubsection{Numerical Optimization}

Numerical optimization of the process was carried out by the Desirability function [25] built through the optimization tool of Design Expert software. Desirability (Equation (9)) is a multiple response method, which provides an overall objective function starting from fitting equations obtained for each response variable (the total desirability, D). D ranges from 0 to 1 , as a geometric mean of the desirable range of each response $\left(\mathrm{d}_{\mathrm{i}}\right)$, which varies from 0 (undesirable value) to 1 (the most desirable value), as well.

$$
\mathrm{D}=\left(\prod_{\mathrm{i}=1}^{\mathrm{n}} \mathrm{d}_{\mathrm{i}}^{\mathrm{r}_{\mathrm{i}}}\right)^{1 / \sum \mathrm{r}_{\mathrm{i}}}
$$


In Equation (9), $r_{i}$ represents the importance that can be assigned by the user (in the software from 1 to 5) for each response variable [26]. The definition of di used in this study, where the purpose is the maximization of the response variables, is given by Equation (8), where $Y_{i}$ is the response variable, and $Y_{i, \min }$ and $Y_{i, \max }$ are the lower and upper value of $Y_{i}[27]$.

$$
d_{i}=\left\{\begin{array}{cc}
0, & Y_{i} \leq Y_{i, \min } \\
\left(\frac{Y_{i}-Y_{i, \min }}{Y_{i, \max }-Y_{i}}\right), & Y_{i, \min }<Y_{i}<Y_{i, \max } \\
1, & Y_{i}>Y_{i, \max }
\end{array}\right.
$$

\subsection{Extract Stabilization by Spray Drying}

Lycopene is a carotenoid of interest in the food industry, being both a food colorant and a strong antioxidant with functional characteristics. However, considering its susceptibility to isomerization and oxidation, and its hydrophobicity, the microencapsulation process is needed to enhance molecule stability, prevent losses of bioactivity and improve bioavailability [28]. Among the microencapsulation processes, spray drying is a consolidated technique widely used in food industry, due to its efficiency, the possibility of continuous production, versatility, and flexibility. Moreover, this technique is suitable for the treatment of thermo-sensitive compounds and provides products with enhanced storage stability due to the low water activity of the product [29]. In addition, by the selection of the proper coating agent, the solubility of encapsulated compounds can be improved. The microencapsulation of lycopene-rich ethanolic extract was carried out by a BÜCHI Mini Spray Dryer B-290 (BÜCHI Labortechnik AG, Flawil, Switzerland) (Figure 1), working by a co-current configuration and equipped with a two-fluid nozzle for the dispersion of the liquid body into fine droplets. The extract $(50 \mathrm{~mL})$ was diluted with $50 \mathrm{~mL}$ of deionized water and homogenized. A mixture of maltodextrins and inulin was used as wall material varying its composition $(21.7,50$ and $78.3 \% w / w$ of inulin) in a concentration of $10 \%(w / v)$ with respect to the diluted extract. Maltodextrins are widely used in encapsulation by spray drying, but do not exhibit remarkable nutraceutical properties as inulin. The selection of the proportion between inulin and maltodextrin was determined by preliminary study (data not shown), which showed that values of inulin higher than $78.3 \% w / w$ in the wall material composition provided a significant reduction in process performances. The lower value was selected basing on the will to work in a symmetric interval of values. The coating agent was dissolved into the liquid extract and left under stirring for $30 \mathrm{~min}$, before starting the microencapsulation tests. The spray dryer worked with an inlet temperature set at $135{ }^{\circ} \mathrm{C}$, an aspiration rate of $32.4 \mathrm{~m}^{3} / \mathrm{h}$, and a feed flow rate of $7.5 \mathrm{~mL} / \mathrm{min}$.

After the spray drying process, obtained microparticles were collected, weighed, and stored in water-proof containers under dark conditions at room temperature, for further analyses.

\section{Product Recovery and Characterization}

The product recovery (PR) was calculated according to Equation (11), as the ratio between the total solids recovered in the collection vessel of the spray dryer and total solids fed to the process.

$$
\mathrm{PR}=\frac{\text { mass of dry microparticles }}{\text { mass of coating agent }+ \text { mass of extract fed }}
$$

The mass of extract fed was determined by drying $4 \mathrm{~mL}$ of the ethanolic extract at $110^{\circ} \mathrm{C}$ up to constant weight, and multiplying the concentration of the extract total solids by the volume of extract fed to the process. 


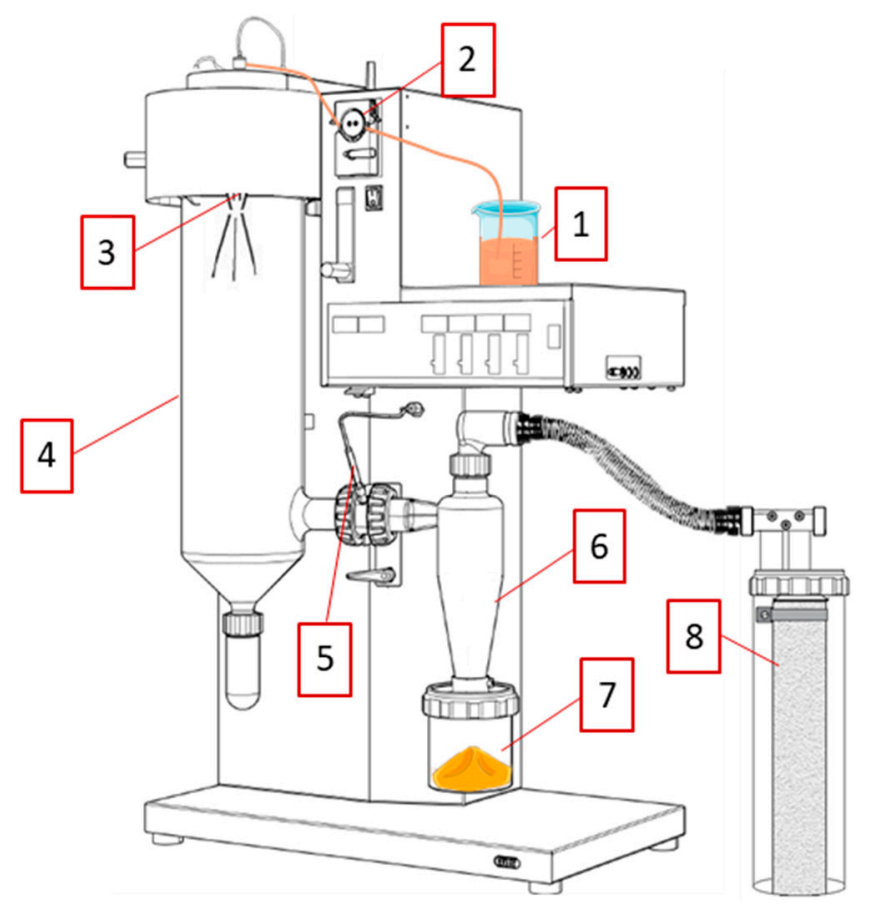

Figure 1. Scheme of spray dryer used for microencapsulation experiments. (1) Liquid feed; (2) peristaltic pump; (3) two-fluid nozzle; (4) drying vessel; (5) thermocouple for outlet temperature detection; (6) cyclone; (7) collection vessel; (8) filter. Adapted from BÜCHI mini spray dryer B-290 operation manual.

The moisture of the produced microparticles was obtained by drying samples at $110^{\circ} \mathrm{C}$ until a constant weight was reached, and it was expressed as mass of water removed by drying per initial mass of wet sample $(\%, w / w)$.

Water activity was measured through a HygroPalm-HP23-AW-A (Rotronic, Crawley, UK).

Total lycopene content in the obtained product was determined after the complete dissolution of the particles. In a glass tube, $15 \mathrm{~mL}$ of $8 \%(v / v)$ acetic acid aqueous solution were added to $400 \mathrm{mg}$ of spray dried particles. This dispersion was vortexed for $1 \mathrm{~min}$ and placed in an ultrasonic bath (model UTA 90, FALC, Treviglio, Italy), working at $25^{\circ} \mathrm{C}$ and $700 \mathrm{~W}$ for $5 \mathrm{~min}$. Then, $5 \mathrm{~mL}$ of chloroform were added to carry out the liquid-liquid extraction of the lycopene in about $12 \mathrm{~h}$. The hydrophobic phase was recovered, while the aqueous phase was subjected to a second stage of liquid-liquid extraction by adding further $5 \mathrm{~mL}$ of chloroform. The non-polar phase was recovered again and added to the previous one. After the chloroform complete evaporation, the dry sample was suspended in $1 \mathrm{~mL}$ of pure ethanol, filtered $(0.22 \mu \mathrm{m})$, and analyzed by HPLC for lycopene quantification. For the determination of superficial lycopene, the method by Robert et al. [30] was adapted, as reported in the following. $400 \mathrm{mg}$ of powder were treated with $1 \mathrm{~mL}$ of pure ethanol and the dispersion was agitated in a vortex at room temperature for $1 \mathrm{~min}$ and filtered $(0.22 \mu \mathrm{m})$. Then, superficial lycopene was determined by HPLC.

Water solubility (WSI) and water absorption (WAI) indexes were determined following the protocol described by Ahmed et al. [31], with some modifications. Briefly, $0.5 \mathrm{~g}$ of microparticles and $6 \mathrm{~mL}$ of water were vigorously vortexed, the mixture was incubated in a water bath at $30^{\circ} \mathrm{C}$ for $30 \mathrm{~min}$, and centrifuged (MF-20-R, Alliance Bio Expertise, Guipry, France) at $2090 \times g$ for $15 \mathrm{~min}$. The pellet obtained was weighed and WAI was calculated according to Equation (12).

$$
\mathrm{WAI}=\frac{\text { mass }_{\text {pellet }}}{\text { mass }_{\text {initial dry sample }}}
$$


Moreover, the supernatant was dried at $110^{\circ} \mathrm{C}$ up to a constant weight, and WSI was obtained from Equation (13).

$$
\text { WSI }=\frac{\text { mass of solids in the supernatant }}{\text { mass of dry sample }}
$$

Finally, the swelling capacity (SWC) was determined according to the protocol reported by Lai et al. [32], as described in Equation (14).

$$
\text { SWC }=\frac{\text { mass }_{\text {pellet }}}{\text { mass }_{\text {initial dried sample }} \cdot(1-\text { WSI })}
$$

\section{Results and Discussion}

\subsection{Characterization of Tomato Waste}

Fresh tomato waste showed a moisture of $84.3 \pm 0.83 \%$, which was reduced after drying $\left(60{ }^{\circ} \mathrm{C}\right)$ up to about $6 \%$ of residual moisture. After grinding, the dried biomass was analyzed in terms of water activity, ash, and mean size. Particularly, after the drying process, the tomato peels exhibited a water activity of $0.101 \pm 0.042$, resulting as suitable for long-term storage in water-proof containers and in the dark for extraction experiments. The biomass showed an ash content of $4.1 \pm 0.8 \%$ and the obtained value agreed with those reported in literature [33-35], while the mean size of ground particles was of $732 \pm 67 \mu \mathrm{m}$.

\subsection{Ultrasound-Assisted Extraction Modelling by RSM}

The simultaneous influence of independent variables on the UAE of total carotenoids and lycopene yields, and on the antiradical power of the obtained extracts, was evaluated through the design of experiments. Table 1 reports the value of the input variables for the 33 runs of the experimental plan and the values of the response variables, reported as the mean value of triplicate analyses \pm standard deviation.

Table 1. Values of the input variables ( $T=$ temperature; $t=$ time; $L / S=$ liquid-to-solid ratio; on = time during which ultrasounds were applied in a cycle (ultrasounds off $=30 \mathrm{~s}$ ); V = total extraction volume) in the Central Composite Design of the ultrasound-assisted extraction process, and experimental results of the response variables $(T C=$ total carotenoid yield; $L Y=$ lycopene yield; $A R P=$ antiradical

\begin{tabular}{|c|c|c|c|c|c|c|c|c|}
\hline$T\left({ }^{\circ} \mathrm{C}\right)$ & $t(\min )$ & $L / S(\mathrm{~mL} / \mathrm{g})$ & $A(\%)$ & on (s) & $V(\mathrm{~mL})$ & $T C\left(\mu \mathrm{g}_{\mathrm{LE}} / \mathrm{g}_{\mathrm{DB}}\right)$ & $L Y\left(\mu g / g_{D B}\right)$ & $A R P\left(\mu g_{\mathrm{TE}} / \mathrm{kg}_{\mathrm{DB}}\right)$ \\
\hline 50 & 35 & 54 & 48 & 50 & 32 & $1268 \pm 7$ & $788 \pm 3$ & $41.31 \pm 1.48$ \\
\hline 35 & 50 & 80 & 30 & 30 & 45 & $1223 \pm 60$ & $579 \pm 6$ & $35.83 \pm 2.62$ \\
\hline 35 & 20 & 80 & 30 & 30 & 90 & $845 \pm 11$ & $257 \pm 5$ & $28.22 \pm 2.25$ \\
\hline 50 & 35 & 54 & 48 & 50 & 68 & $890 \pm 26$ & $523 \pm 21$ & $30.28 \pm 0.98$ \\
\hline 35 & 20 & 80 & 65 & 70 & 90 & $761 \pm 11$ & $442 \pm 15$ & $31.07 \pm 1.45$ \\
\hline 65 & 20 & 27 & 65 & 30 & 45 & $1252 \pm 15$ & $655 \pm 6$ & $25.90 \pm 1.77$ \\
\hline 35 & 20 & 27 & 30 & 30 & 45 & $700 \pm 24$ & $391 \pm 20$ & $16.69 \pm 0.58$ \\
\hline 65 & 20 & 80 & 65 & 30 & 90 & $1206 \pm 21$ & $1008 \pm 41$ & $39.16 \pm 1.80$ \\
\hline 50 & 35 & 54 & 20 & 50 & 68 & $818 \pm 26$ & $510 \pm 14$ & $29.43 \pm 1.34$ \\
\hline 50 & 35 & 54 & 48 & 50 & 68 & $991 \pm 11$ & $665 \pm 0$ & $32.42 \pm 2.74$ \\
\hline 27 & 35 & 54 & 48 & 50 & 68 & $764 \pm 28$ & $587 \pm 26$ & $23.76 \pm 0.85$ \\
\hline 35 & 50 & 80 & 65 & 70 & 45 & $1093 \pm 75$ & $770 \pm 10$ & $40.27 \pm 2.44$ \\
\hline 50 & 35 & 54 & 48 & 81 & 68 & $1038 \pm 31$ & $806 \pm 12$ & $37.78 \pm 1.34$ \\
\hline 50 & 35 & 54 & 75 & 50 & 68 & $1206 \pm 25$ & $1011 \pm 16$ & $39.59 \pm 2.18$ \\
\hline 65 & 50 & 27 & 65 & 30 & 90 & $1553 \pm 20$ & $1035 \pm 48$ & $34.14 \pm 2.60$ \\
\hline 65 & 20 & 80 & 30 & 70 & 90 & $1155 \pm 51$ & $801 \pm 54$ & $28.85 \pm 2.39$ \\
\hline 35 & 50 & 27 & 30 & 30 & 90 & $826 \pm 24$ & $556 \pm 41$ & $14.98 \pm 0.65$ \\
\hline 50 & 58 & 54 & 48 & 50 & 68 & $1217 \pm 8$ & $1016 \pm 39$ & $27.82 \pm 2.25$ \\
\hline 50 & 12 & 54 & 48 & 50 & 68 & $1112 \pm 13$ & $818 \pm 23$ & $23.86 \pm 0.81$ \\
\hline 50 & 35 & 54 & 48 & 19 & 68 & $1174 \pm 42$ & $785 \pm 23$ & $25.90 \pm 0.98$ \\
\hline
\end{tabular}
power). Data are reported as mean value of triplicate analyses \pm standard deviation. 
Table 1. Cont.

\begin{tabular}{|c|c|c|c|c|c|c|c|c|}
\hline$T\left({ }^{\circ} \mathrm{C}\right)$ & $t$ (min) & $L / S(\mathrm{~mL} / \mathrm{g})$ & $A(\%)$ & on (s) & $V(\mathrm{~mL})$ & $T C\left(\mu \mathrm{g}_{\mathrm{LE}} / \mathrm{g}_{\mathrm{DB}}\right)$ & $L Y\left(\mu \mathrm{g} / \mathrm{g}_{\mathrm{DB}}\right)$ & $A R P\left(\mu \mathrm{g}_{\mathrm{TE}} / \mathrm{kg}_{\mathrm{DB}}\right)$ \\
\hline 65 & 50 & 80 & 65 & 30 & 45 & $1024 \pm 28$ & $704 \pm 8$ & $36.15 \pm 2.39$ \\
\hline 50 & 35 & 54 & 48 & 50 & 103 & $856 \pm 23$ & $693 \pm 39$ & $26.11 \pm 1.21$ \\
\hline 50 & 35 & 54 & 48 & 50 & 68 & $752 \pm 5$ & $723 \pm 45$ & $23.65 \pm 0.18$ \\
\hline 50 & 35 & 12 & 48 & 50 & 68 & $751 \pm 4$ & $344 \pm 2$ & $9.51 \pm 0.30$ \\
\hline 50 & 35 & 54 & 48 & 50 & 68 & $796 \pm 8$ & $531 \pm 39$ & $24.93 \pm 1.03$ \\
\hline 65 & 20 & 27 & 30 & 70 & 45 & $817 \pm 33$ & $476 \pm 13$ & $17.01 \pm 1.43$ \\
\hline 35 & 20 & 27 & 65 & 70 & 45 & $555 \pm 4$ & $312 \pm 12$ & $16.9 \pm 1.07$ \\
\hline 50 & 35 & 95 & 48 & 50 & 68 & $787 \pm 37$ & $532 \pm 0$ & $25.23 \pm 1.63$ \\
\hline 50 & 35 & 54 & 48 & 50 & 68 & $732 \pm 36$ & $493 \pm 5$ & $23.65 \pm 1.21$ \\
\hline 35 & 50 & 27 & 65 & 70 & 90 & $648 \pm 10$ & $242 \pm 47$ & $19.42 \pm 1.12$ \\
\hline 65 & 50 & 80 & 30 & 70 & 45 & $723 \pm 12$ & $552 \pm 10$ & $30.60 \pm 1.37$ \\
\hline 65 & 50 & 27 & 30 & 70 & 90 & $700 \pm 16$ & $473 \pm 0$ & $21.78 \pm 0.33$ \\
\hline 73 & 35 & 54 & 48 & 50 & 68 & $895 \pm 35$ & $710 \pm 11$ & $33.92 \pm 0.98$ \\
\hline
\end{tabular}

$\mathrm{LE}=$ lycopene equivalents; $\mathrm{DB}=$ dried biomass; $\mathrm{TE}=$ trolox equivalents.

The total carotenoid yields ranged from 555 to $1553 \mu \mathrm{g}_{\mathrm{LE}} / \mathrm{g}_{\mathrm{DB}}$ showing a strong variability as a function of the investigated input variables. A previous study [36], concerning the recovery of carotenoids from waste of tomato industry, investigated the effect of different solvents by conventional extraction process, obtaining a TC of $17.57 \mathrm{mg} \mathrm{LE} / \mathrm{kg}$ dry tomato waste using ethanol as solvent, while the maximum TC of $243.00 \mathrm{mg}_{\mathrm{LE}} / \mathrm{kg}$ dry tomato waste was provided by ethyl lactate (three solid-to-liquid extractions in series, liquid-to-solid ratio 1:10 $\mathrm{w} / \mathrm{v}$, temperature $70{ }^{\circ} \mathrm{C}$, time $30 \mathrm{~min}$ ). Therefore, it can be noted that the reported yields were much lower than those obtained in the present study by UAE. In fact, the use of ultrasounds allows an increase in the extraction yield, and a reduction in the use of solvent and process times, with respect to the conventional solvent extraction (SE). Luengo et al. [6] used manosonication-assisted extraction to improve carotenoids extraction yields, and a maximum TC of $14.08 \mathrm{mg}_{\mathrm{LE}} / 100 \mathrm{~g}_{\text {Dry solid }}$ was obtained at $45^{\circ} \mathrm{C}$, using hexane/ethanol $50 / 50 \mathrm{v} / \mathrm{v}$ as solvent, showing the effect of ultrasounds in being able to reduce the temperature needed for the extraction compared to the conventional process. However, positive effects of pressure should be also considered, as reported for the recovery of lycopene by supercritical fluid extraction using ethanol $5 \%$ as co-solvent (up to $77.2 \%$ lycopene recovery) [37], and pressurized liquid extraction [38] with lycopene yields up to $41.74 \pm 3.38 \mathrm{mg} / 100 \mathrm{~g}$ using ethanol $75 \%$ as solvent.

TC was modeled according to a reduced quadratic model (Equation (15)) and analysis of variance (ANOVA) was performed (Table 2) to assess the significance of the model and equation terms.

$$
\begin{aligned}
& \sqrt{T C}=0.96+0.023 T+0.016 t+6.464 \cdot 10^{-3} \frac{L}{S}+0.040 A-0.021 \text { on }-0.064 V-0.048 T \cdot t-0.046 T \cdot \frac{L}{S}+ \\
& \quad+0.048 T \cdot A+0.036 T \cdot V-0.074 t \cdot \frac{L}{S}-0.031 t \cdot V+0.032 \frac{L}{S} \cdot \text { on }-0.034 A \cdot \text { on }+0.042 t^{2}-0.041\left(\frac{L}{S}\right)^{2}
\end{aligned}
$$

$A, T \cdot t, T \cdot L / S, t^{2}$ were the most significant terms $(p$-value $<0.05)$ of the model, which resulted as significant ( $p=0.0032)$ with no significant lack of fit $(p=0.3020)$, and adequately represented the experimental data within the design space $\left(R^{2}=0.8081\right) . A d j R^{2}$ presented a lower value, due to the number of not significant terms which were still present in the equation to support the hierarchy. A presented a positive value of the coefficient, indicating that the higher its value, the higher the TC, while the interaction terms of $T \cdot t$ and $T \cdot L / S$ showed a negative value of the coefficients, as well as the quadratic term of the $L / S$.

The highest value of $T C$ was experimentally found at $65{ }^{\circ} \mathrm{C}$, with $50 \mathrm{~min}$ as the extraction time, low $L / S(27)$, high $A(65 \%)$ and $V(90 \mathrm{~mL})$, and low on $(30 \mathrm{~s})$. 
Table 2. Model for total carotenoid yield (TC) as a function of input variables and analysis of variance.

\begin{tabular}{|c|c|c|c|c|}
\hline Source & Coefficient Coded Value & $\begin{array}{l}\text { Cofficient } \\
-95 \% \text { C.I. }\end{array}$ & $\begin{array}{l}\text { Cofficient } \\
+95 \% \text { C.I. }\end{array}$ & $p$-Value \\
\hline Model & & & & 0.0032 \\
\hline Intercept & 0.96 & 0.92 & 1.01 & \\
\hline$T$ & 0.023 & -0.047 & 0.093 & 0.4965 \\
\hline$t$ & 0.016 & -0.018 & 0.050 & 0.3317 \\
\hline$L / S$ & $6.464 \times 10^{-3}$ & -0.064 & 0.077 & 0.8480 \\
\hline$A$ & 0.040 & $5.532 \times 10^{-3}$ & 0.074 & 0.0254 \\
\hline on & -0.021 & -0.091 & 0.050 & 0.5430 \\
\hline$V$ & -0.064 & -0.13 & $6.222 \times 10^{-3}$ & 0.0712 \\
\hline$T \cdot t$ & -0.048 & -0.087 & $-8.696 \times 10^{-3}$ & 0.0196 \\
\hline$T \cdot L / S$ & -0.046 & -0.085 & $-7.073 \times 10^{-3}$ & 0.0234 \\
\hline$T \cdot A$ & 0.048 & -0.033 & 0.13 & 0.2249 \\
\hline$T \cdot V$ & 0.036 & $-2.667 \times 10^{-3}$ & 0.075 & 0.0658 \\
\hline$T \cdot L / S$ & -0.074 & -0.15 & $6.224 \times 10^{-3}$ & 0.0682 \\
\hline$t \cdot V$ & -0.031 & -0.11 & 0.050 & 0.4293 \\
\hline$L / S \cdot o n$ & 0.032 & $-7.062 \mathrm{E} \times 10^{-3}$ & 0.071 & 0.1019 \\
\hline A.on & -0.034 & -0.11 & 0.046 & 0.3764 \\
\hline$t^{2}$ & 0.042 & $6.013 \times 10^{-4}$ & 0.083 & 0.0471 \\
\hline$L / S^{2}$ & -0.041 & -0.082 & $5.692 \times 10^{-4}$ & 0.0529 \\
\hline$R^{2}$ & 0.8081 & & & \\
\hline $\operatorname{Adj} R^{2}$ & 0.6162 & & & \\
\hline Lack of Fit & & & & 0.3020 \\
\hline
\end{tabular}

Lycopene content was found in the range $242-1035 \mu \mathrm{g} / \mathrm{g}_{\mathrm{DB}}$, and the highest value was found under the same conditions maximizing $T C$. The regression equation showing the dependence of $L Y$ from input variables (Equation (13)) is reported in Table 3, where the results of ANOVA indicated that the model was significant with no significant lack of fit, and in good agreement with experimental data. $L / S, A, T V, L / S$ on and $(L / S)^{2}$ were the terms which more significantly affected the response variable, exhibiting positive coefficients, with exception given for the quadratic term of $L / S$.

Table 3. Model for lycopene yield $(L Y)$ as a function of input variables and analysis of variance.

\begin{tabular}{|c|c|c|c|c|}
\hline Source & Coefficient Coded Value & $\begin{array}{l}\text { Cofficient } \\
-95 \% \text { C.I. }\end{array}$ & $\begin{array}{l}\text { Cofficient } \\
+95 \% \text { C.I. }\end{array}$ & $p$-Value \\
\hline Model & & & & 0.0001 \\
\hline Intercept & 25.79 & 24.40 & 27.18 & \\
\hline$T$ & 0.77 & -1.50 & 3.05 & 0.4855 \\
\hline$t$ & 0.86 & -0.24 & 1.97 & 0.1174 \\
\hline$L / S$ & 1.34 & 0.24 & 2.45 & 0.0194 \\
\hline$A$ & 1.61 & 0.51 & 2.71 & 0.0065 \\
\hline on & 0.12 & -2.16 & 2.39 & 0.9147 \\
\hline$V$ & 0.035 & -1.07 & 1.14 & 0.9482 \\
\hline$T \cdot t$ & -1.25 & -2.51 & 0.014 & 0.0523 \\
\hline$T \cdot A$ & 1.50 & -1.10 & 4.10 & 0.2426 \\
\hline$T \cdot V$ & 1.85 & 0.59 & 3.11 & 0.0062 \\
\hline$L / S \cdot o n$ & 1.66 & 0.40 & 2.92 & 0.0125 \\
\hline$A \cdot o n$ & -2.10 & -4.70 & 0.50 & 0.1077 \\
\hline$t^{2}$ & 1.09 & -0.25 & 2.42 & 0.1052 \\
\hline$L / S^{2}$ & -2.77 & -4.10 & -1.43 & 0.0004 \\
\hline$R^{2}$ & 0.8226 & & & \\
\hline $\operatorname{Adj} R^{2}$ & 0.7013 & & & \\
\hline Lack of Fit & & & & 0.3792 \\
\hline
\end{tabular}




$$
\begin{aligned}
\sqrt{L Y}=25.79+ & 0.77 \mathrm{~T}+0.86 t+1.34 \frac{L}{S}+1.61 A-0.12 \text { on }+0.035 V-1.25 \mathrm{Tt}+1.5 \mathrm{TA} \\
& +1.85 \mathrm{TV}+1.66 \frac{\mathrm{L}}{\mathrm{S}} \cdot \mathrm{on}-2.10 \mathrm{~A} \cdot \mathrm{on}+1.09 t^{2}-2.77\left(\frac{L}{S}\right)^{2}
\end{aligned}
$$

Rahimi and Mikani [8] carried out a study on the process parameters of UAE using sunflower oil as solvent, evaluating the lycopene recovery by varying the solid to liquid ratio, the process time, and the ultrasound intensity. The highest extraction yield $(87.25 \%$, $91.49 \mathrm{mg}_{\mathrm{LE}} / 100 \mathrm{~g}_{\text {dried tomato waste }}$ ) was provided by an ultrasound intensity of $70 \mathrm{~W} / \mathrm{m}^{2}$, an extraction time of $10 \mathrm{~min}$, and a ratio of dried tomato waste to oil equal to 20 . Their results only partially agreed with the findings of the present study, since the ratio of dried tomato waste to oil was the less significant parameter, while a strong dependence was found in this study on the liquid-to-solid ratio. However, it could depend on an increased total extraction volume as the ratio of dried tomato waste to oil was decreased, a factor which can potentially influence the extraction performances, and which was considered as a further variable in this study. Indeed, results reported by Kumcuoglu et al. [39] showed the significant influence of the lycopene ultrasound-assisted extraction yield from the liquidto-solid ratio, which was changed by maintaining the total extraction volume constant at $40 \mathrm{~mL}$.

The ARP model (Equation (17)) and the related ANOVA are shown in Table 4.

$$
\begin{aligned}
\sqrt{A R P} & =5.25+0.22 T+0.16 t+0.63 \frac{L}{S}+0.29 A-0.26 \text { on }-0.42 V-0.21 T \cdot \frac{L}{S} \\
& +0.40 T \cdot A+0.17 T \cdot V-0.42 t \cdot \frac{L}{S}-0.51\left(\frac{L}{S}\right)^{2}+0.23 A^{2}+0.19 V^{2}
\end{aligned}
$$

The model was significant, with not significant lack of fit. All the linear terms of the equation exhibited a $p$-value $<0.05$ as well as the reported interactive and quadratic terms.

\begin{tabular}{|c|c|c|c|c|}
\hline Source & Coefficient Coded Value & $\begin{array}{l}\text { Cofficient } \\
-95 \% \text { C.I. }\end{array}$ & $\begin{array}{l}\text { Cofficient } \\
+95 \% \text { C.I. }\end{array}$ & $p$-Value \\
\hline Model & & & & $<0.0001$ \\
\hline Intercept & 5.25 & 5.11 & 5.40 & \\
\hline$T$ & 0.22 & 0.11 & 0.33 & 0.0004 \\
\hline$t$ & 0.16 & 0.051 & 0.27 & 0.0064 \\
\hline$L / S$ & 0.63 & 0.52 & 0.74 & $<0.0001$ \\
\hline$A$ & 0.29 & 0.18 & 0.40 & $<0.0001$ \\
\hline on & 0.26 & 0.032 & 0.48 & 0.0273 \\
\hline$V$ & -0.42 & -0.65 & -0.19 & 0.0010 \\
\hline$T \cdot L / S$ & -0.21 & -0.33 & -0.081 & 0.0027 \\
\hline$T \cdot A$ & 0.40 & 0.15 & 0.66 & 0.0040 \\
\hline$T \cdot V$ & 0.17 & 0.047 & 0.30 & 0.0098 \\
\hline$t \cdot L / S$ & -0.42 & -0.68 & -0.16 & 0.0029 \\
\hline$L / S^{2}$ & -0.51 & -0.64 & -0.37 & $<0.0001$ \\
\hline$A^{2}$ & 0.23 & 0.097 & 0.37 & 0.0019 \\
\hline$V^{2}$ & 0.19 & 0.060 & 0.33 & 0.0069 \\
\hline$R^{2}$ & 0.9448 & & & \\
\hline $\operatorname{Adj} R^{2}$ & 0.9070 & & & \\
\hline Lack of Fit & & & & 0.9885 \\
\hline
\end{tabular}
The absence of not significant terms in the reduced quadratic model enabled very good experimental data fitting $\left(R^{2}=0.9448 ; A d j R^{2}=0.9070\right)$.

Table 4. Model for antiradical power $(A R P)$ as a function of input variables and analysis of variance.

The ARP of extracts obtained under different operating conditions can be ascribed not only to extracted carotenoids, but also to polyphenols (mainly $p$-coumaric and chlorogenic acid derivatives) [40] and amino acids, whose synergistic effects and interactions are able to provide enhanced bioactivity over single compounds [41]. The obtained values of $A R P$ 
ranged between $9.51 \pm 0.30$ and $41.31 \pm 1.48 \mu \mathrm{g}_{\mathrm{TE}} / \mathrm{kg}_{\mathrm{DB}}$, exhibiting a strong variability with respect to the selected operating variables.

\subsection{Process Optimization}

By means of Equations (15)-(17) it was possible to build the desirability function in order to investigate the combined effects of all the operating conditions investigated. The response variables were maximized by assigning the highest importance to $(5 / 5)$ to $L Y$, followed by ARP $(4 / 5)$ and TC (3/5), while the values of the input variables where the best solution was found were in the same range of the experimental session, with exception given for the total volume. Indeed, process optimization was also imposed to maximize this variable (importance $3 / 5$ ) in order to understand the maximum volume treatable with the same energy input without significant losses in extraction yields. The desirability function dependence on input variables is reported in Figure 2. Surface plots on the same row (e.g., Figure $2 \mathrm{a}, \mathrm{d}, \mathrm{g}$ ) show the same input variables on the axes, while the columns report the minimum (Figure $2 \mathrm{a}-\mathrm{c}$ ), optimal (Figure $2 \mathrm{~d}-\mathrm{f}$,) and maximum (Figure $2 \mathrm{~g}-\mathrm{i}$ ) values of the operating conditions in the selected design space. The strong interdependence of the operating conditions was revealed by the shape changes of the surface in correspondence with the minimum (Figure $2 \mathrm{a}-\mathrm{c}$, ) and maximum (Figure 2g-i) values of the variables. Extraction time is one of the most important variables in this kind of separation process, and the higher the contact time between the solid particles and the solvent, the higher the mass transfer achieved. Nevertheless, extraction kinetics often show a plateau, and times longer than the critical value do not provide a significant enhancement in extraction yields. Furthermore, when thermo-sensitive compounds are involved in the process, degradation kinetics should be taken into account. Conflicting effects of extraction times were reported by several authors. For instance, positive effects of prolonged time in UAE were found for the recovery of polyphenols and phlorotannin from brown seeds [42] and lycopene from tomato [7,35], as well as for flavonoids from Lycium barbarum up to $90 \mathrm{~min}$ [43], while a reduced concentration of polyphenols from mango residues was observed by prolonging the time from 20 to $30 \mathrm{~min}$ [44], of anthocyanins from pigmented rice after $20 \mathrm{~min}$ [45], and a slight decrease in lycopene yield from tomato was also observed in improved ultrasound-assisted extraction after $20 \mathrm{~min}$ of sonication [46].

Moreover, no significant effects of time were reported by Grassino et al. [4] in the recovery of polyphenols and flavonoids from tomato waste. Generally, the increase in sonication time initially shows positive effects, then the yields tend to decrease at long times [12]. However, both degradation and extraction kinetics parameters are always functions of the other operating conditions, such as temperature and ultrasound amplitude, so the system behavior over time can strongly change by varying UAE parameters, as observed in this study.

Temperature's ability to improve mass transfer in solid-liquid extraction is well known in literature [47]. However, in UAE, other contributions of this parameter are involved. Indeed, if an increase in system temperature initially provides a higher extraction yield due to the higher solubility and diffusivity of compounds in the liquid medium and the lower solvent viscosity, on the other hand, it causes a rise in solvent vapor pressure and a reduction in solvent surface tension. Consequently, more solvent vapor enters in the bubble cavity, and numerous cavitation bubbles are generated, so the violence of the collapse is reduced, weakening the sonochemical effects [12,48]. Moreover, lycopene stability and antioxidant activity can be negatively impacted by the higher temperature adopted. The structure of lycopene makes it susceptible to degradation because of its conjugated double bonds. However, it has been reported that the compound is quite stable at temperatures below $60{ }^{\circ} \mathrm{C}$ [49,50]. Liao et al. [46] obtained the highest $L Y$ at $25^{\circ} \mathrm{C}$, and lower values were attained at higher temperatures, whereas Lianfu and Zelong [5] reported an increase in $L Y$ as temperature rose from 54 to $84{ }^{\circ} \mathrm{C}$. The need to ensure both high extraction yields and 
the preservation of the biological activity of the compounds often requires finding the right compromise by an optimization process.
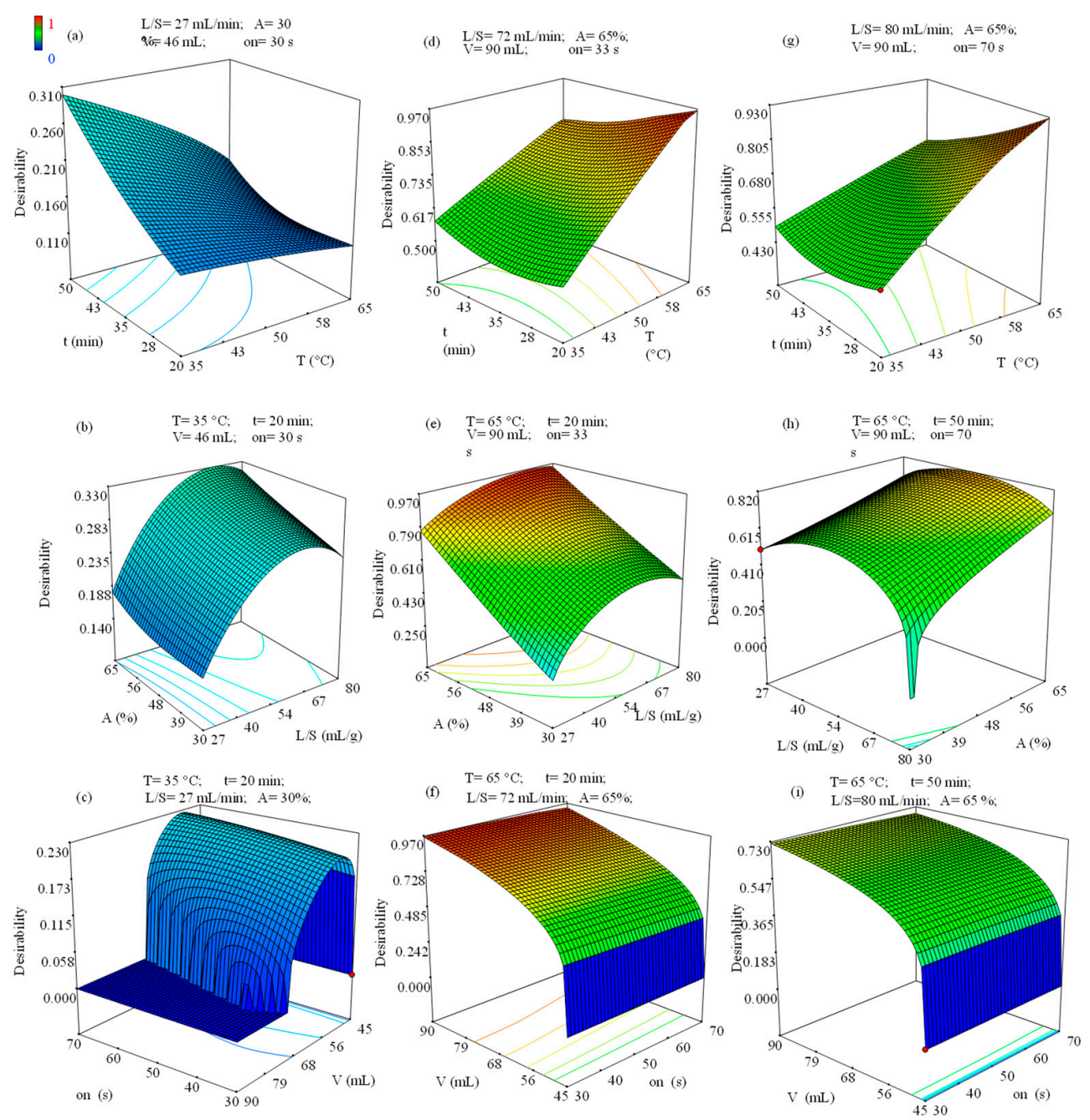

Figure 2. Surface plots of desirability as a function of the input variables: temperature $(T)$, time $(t)$, ultrasound amplitude $(A)$, on/ off pulsed ratio (on), liquid-to-solid ratio $(L / S)$, and volume $(V)$.

Amplitude is a measure of the power delivered. Usually, the yield of extraction increases with power, due to the larger amplitude of ultrasound traveling through the solvent which provokes more intense bubble implosion and sonochemical effects on the solid particles [12], including particle fragmentation which increases the surface area [51], enhancing the process performance. However, after reaching a peak, sometimes extraction yields tend to decrease with the further increase in amplitude [51]. When the power increases to a very high level, it leads to an increase in the number of bubbles formed, and the collapse occurs non-spherically, decreasing the impact of the implosion. Furthermore, the layer of cavitation bubbles around the tip of the probe hinders the transmission of energy in the extraction medium, reducing the yield [12,44,48]. An increase from Figure 2b,e,h can be observed as the positive effect of amplitude rise throughout the investigated design space. This result is in agreement with the findings of other studies [6,46]. The on/off pulsed ratio was a useful parameter to control temperature inside the system. Compared to continuous ultrasound application, the process operating in pulsed mode decreases the number of cavitation bubbles but increases the intensity of their implosion [12]. However, this was the parameter that less affected the response variables (Tables 2-4) and the desirability, as can be observed in Figure 2c,f,i. The larger the liquid-to-solid ratio, the higher the mass of compounds that can be transferred in the liquid solvent, due to a favorable 
concentration gradient during the diffusion and the lower viscosity of the system enhancing the cavitation effect [12]. As can be seen in the desirability surface plots (Figure 2b,e,h), the objective function value initially increased with $L / S$ up to a maximum value, beyond which it decreased. This effect can be traced back to the maximum of mass transfer reached, as well as to the degradation effects precisely due to the high cavitation effect resulting in degradation of the desirable solute [12,39]. Total extraction volume is an important parameter for UAE, since it is related to the power density. The importance of this parameter is highlighted by some troubles encountered in the ultrasound-assisted process scale-up [52], also related to the industry-available sonic probes [48]. Keeping a constant liquid-to-solid ratio with the other investigated parameter, all the extraction yields decreased as the system volume increased (Figure 3a-c). Indeed, as reported by Kulkarni and Rathod [53], the lower extraction yields with the increase in the liquid volume could be due to a decrease in power density and ultrasound efficiency due to the scatter of ultrasonic energy in bulk solution, while low sonication volume leads more collisions among particles, increasing the total area exposed to solvent extraction. The only exception was given by $L Y$ which, at low temperatures, agreed with the other response variables (Figure 3c) despite showing an opposite shape when temperature was increased above $50{ }^{\circ} \mathrm{C}$ (Figure $3 \mathrm{~d}$ ). This evidence could be related to the selectivity toward lycopene induced by the variation volume, and therefore to the power applied [48].

(a)

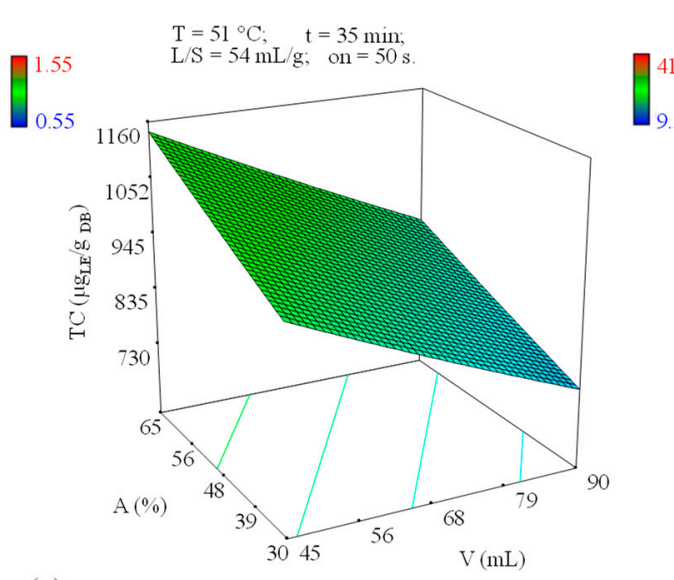

(c)

$\prod_{242}^{1035}$

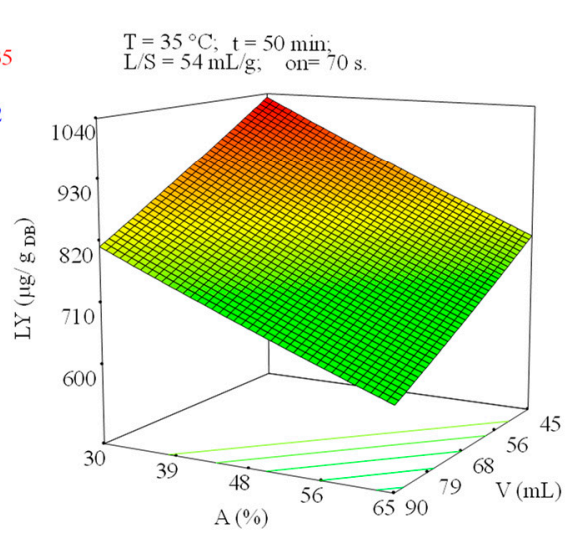

(b)

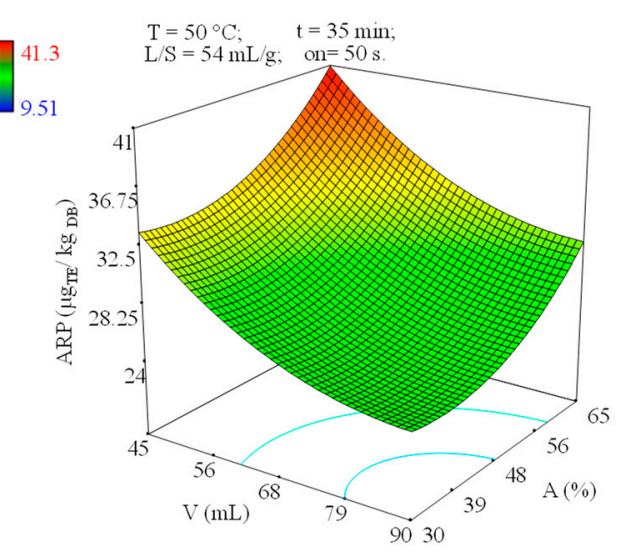

(d)

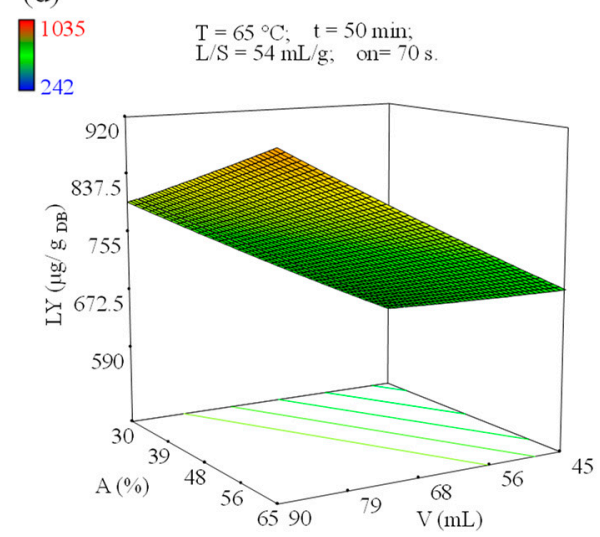

Figure 3. Surface plots of: (a) total carotenoid yield (TC); (b) antiradical power (ARP); and $(\mathbf{c}, \mathbf{d})$ lycopene yield as functions of amplitude $(A)$ and total volume $(V)$.

Numerical optimization under the abovementioned constraints led to the optimum values of the input variables reported in Table 5. As shown in Figure 4, the optimal solution numerically found allowed the obtainment of a global desirability of 0.964 , being particularly favorable in maximizing $L Y$ and $A R P$. The optimal point was experimentally verified, and results were very close to those predicted by the model. Only the $L Y$ result 
was significantly higher than the value mathematically predicted. This discrepancy could be due to the non-homogeneous lycopene content in the matrix.

Table 5. Results of numerical optimization and experimental verification.

\begin{tabular}{|c|c|c|c|}
\hline Variables & Optimized Values & $\begin{array}{l}\text { Response Variable Values } \\
\text { Predicted by Model }\end{array}$ & $\begin{array}{l}\text { Response Variable Values } \\
\text { Experimentally Verified }\end{array}$ \\
\hline$T\left({ }^{\circ} \mathrm{C}\right)$ & 65 & & \\
\hline$t(\min )$ & 20 & & \\
\hline$L / S(\mathrm{~mL} / \mathrm{g})$ & 72 & & \\
\hline$A(\%)$ & 65 & & \\
\hline on (s) & 33 & & \\
\hline$V(\mathrm{~mL})$ & 90 & & \\
\hline$T C\left(\mu \mathrm{g}_{\mathrm{LE}} / \mathrm{g}\right)$ & & 1402 & $1408 \pm 14$ \\
\hline$L Y(\mu \mathrm{g} / \mathrm{g})$ & & 1140.39 & $1536 \pm 53$ \\
\hline$A R P\left(\mu \mathrm{g}_{\mathrm{TE}} / \mathrm{kg}\right)$ & & 39.8 & $36.1 \pm 0.9$ \\
\hline
\end{tabular}

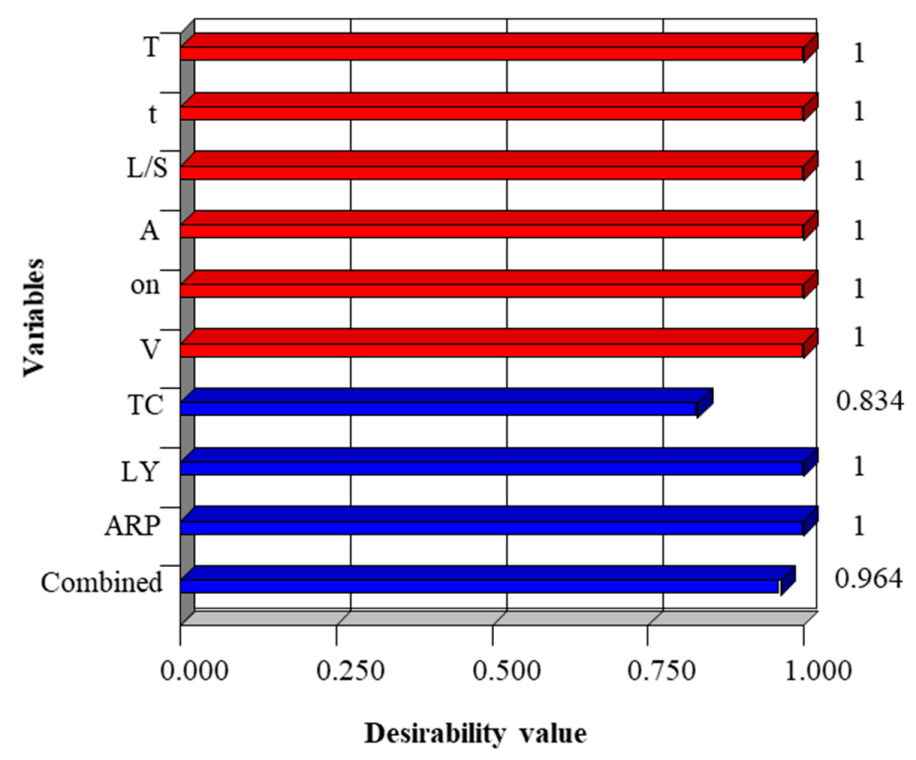

Figure 4. Desirability values for the input and response variables.

\subsection{Extract Stabilization by Spray Drying}

Thermo-sensitivity of carotenoids made them highly unstable and susceptible to losses of activity during processing and storage [54]. Encapsulation by spray drying allowed protection against degradation and the modulation of active compound release, providing a dry product suitable for storage.

For this reason, the extract obtained under the optimal condition was spray dried using a mixture of maltodextrins $(78.3 \%, w / w)$ and inulin $(21.7 \%, w / w)$ as wall material. Maltodextrins are polysaccharides widely used as a food additive and flavor enhancer due to their high water solubility, low viscosity, and the ability to provide colorless solution [30]. Although they are often employed alone in microencapsulation processes by spray drying, the combination with other wall materials can improve the properties of the obtained products. Indeed, a coating agent enriched by inulin can confer nutritive properties to the product without impacting raw materials costs [54].

As shown in Figure 5, microencapsulation was carried out by setting an inlet temperature of $135^{\circ} \mathrm{C}$, in order to reduce lycopene thermal damage. Heating time, up to the set point temperature, occurred in $8 \mathrm{~min}$; then, the feed started to be spread into the drying chamber. The drying process was conducted for about $14 \mathrm{~min}$, while $5 \mathrm{~min}$ were required for the cooling stage up to $55^{\circ} \mathrm{C}$. 


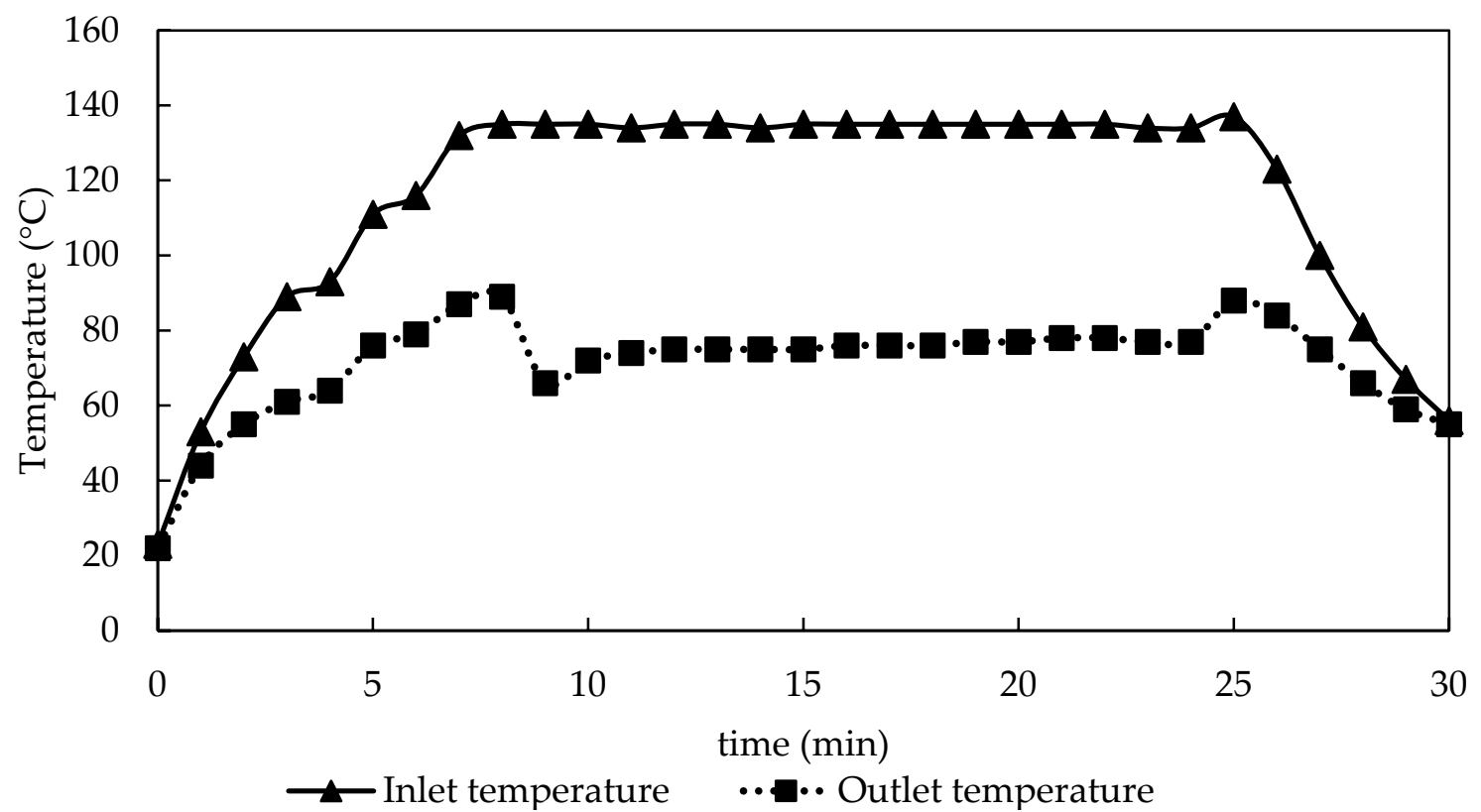

Figure 5. Inlet and outlet temperatures recorded over time during spray drying test.

Results of analyses on the collected dry microparticles are reported in Table 6, as a function of inulin content in the mixture composing the coating agent.

Table 6. Characterization of the dry particles produced by spray drying.

\begin{tabular}{llll}
\hline & $\mathbf{2 1 . 7 \%}$ Inulin & $\mathbf{5 0 \%}$ Inulin & $\mathbf{7 8 . 3 \%}$ Inulin \\
\hline Product recovery $(\%)$ & $73 \pm 4$ & $64 \pm 3$ & $63 \pm 3$ \\
Moisture (\%) & $3.2 \pm 0.1$ & $2.5 \pm 0.4$ & $2.9 \pm 0.3$ \\
Water activity (-) & $0.239 \pm 0.001$ & $0.217 \pm 0.023$ & $0.220 \pm 0.000$ \\
Total lycopene content $(\mu \mathrm{g} / \mathrm{g}$ dry powder) & $15.6 \pm 2.9$ & $0.8 \pm 0.3$ & $1.1 \pm 0.1$ \\
Superficial lycopene $\mu \mathrm{\mu g} / \mathrm{g}$ dry powder) & $0.30 \pm 0.02$ & $0.7 \pm 0.2$ & $1.1 \pm 0.1$ \\
Encapsulated lycopene ( $\mu$ g/g dry powder) & $15.3 \pm 2.9$ & $0.1 \pm 0.4$ & $0.0 \pm 0.1$ \\
Water solubility index (WSI) & $0.935 \pm 0.007$ & $0.858 \pm 0.006$ & $0.643 \pm 0.012$ \\
Water absorption index (WAI) & $0.376 \pm 0.027$ & $0.800 \pm 0.050$ & $1.78 \pm 0.002$ \\
Swelling capacity (SWC) & $5.79 \pm 0.25$ & $5.635 \pm 0.315$ & $4.98 \pm 0.17$ \\
\hline
\end{tabular}

The low moisture and water activity of the microparticles are favorable to ensure a good shelf life of the product at room temperature, away from light. Moisture results in this work are in agreement with the study by Fernandes et al. [55]. Non-significant differences in moisture and water activity were observed by varying the composition of the wall material. The process ensured a good product recovery in comparison with values reported in the literature for spray drying processes [16,56-59], particularly at the lower inulin content. The same experimental point provided a satisfying amount of encapsulated lycopene compared to the superficial (and unprotected) content, which strongly decreased with the increase in inulin percentage. However, an optimization of the spray drying process could improve the encapsulation of the extract and the amount of active agent in the particles, which resulted lower than that reported in the literature $[60,61]$. The lycopene losses during the process can be traced back to the low solubility of the compound in the feed, where the extract was diluted with water and a low concentration of coating agent in the feed, rather than being due to degradation effects, considering the low temperature inside the drying chamber. Powder solubility depends on many parameters, such as the coating agent composition and spray drying operating conditions, and it determines the potential applications of the product. WSI gives information about the behavior of the product in the aqueous phase [62], while WAI measures the volume occupied by the wall material after swelling in excess of water [63]. The product presents high water solubility 
at the lowest inulin concentration, while a decrease was observed as the percentage in the used wall material increased, being the compound less soluble than maltodextrin in aqueous media. However, up to $50 \%$ inulin, WSI was higher than the reported value for lycopene microencapsulation in maltodextrin, whey protein isolate, and modified starch by Souza et al. [61].

\section{Conclusions}

In this work, an experimental study on the recovery of bioactive compounds using tomato peels and seeds from tomato processing was undertaken. The recovery and reintegration of carotenoids in food products in the form of additives fits the strategy for sustainability and the circular economy. Response surface modelling and desirability methods were applied to evaluate the effect of the operating conditions of ultrasoundassisted extraction using ethanol as solvent. The results showed that in UAE the operating conditions are strongly interconnected, and the dependence of extraction performances from the process variables are more complex when all the process variables are evaluated simultaneously. Optimization was carried out by maximizing lycopene yield, total carotenoids, antiradical power of the extract, and the volume of suspension that can be processed. The results of the optimization showed that high temperature, amplitude, liquid-to-solid ratio, system volume, short time and on/off pulsed ratio provide a high lycopene recovery of $1536 \pm 53 \mu \mathrm{g} / \mathrm{g}$. Under these conditions, a good desirability value was obtained, which simultaneously maximized all the response variables selected and the optimization constraints.

Furthermore, a feasibility evaluation of the encapsulation of the obtained extract by spray drying was carried out, investigating the possibility to add inulin in the composition of the wall material. The best results were obtained at the lowest percentage of inulin (21.7\% inulin and $78.3 \%$ of maltodextrins). Despite the high product recovery, low water activity, higher content of encapsulated than superficial lycopene of the microparticles, and good water solubility, the spray drying process deserves further investigations to enhance process performances.

Author Contributions: Conceptualization, M.P.; methodology, M.P. and A.A.C.; software, M.P.; validation, A.A.C., J.L. and M.P.; formal analysis, J.L.; investigation, M.P., J.L. and A.A.C.; resources, P.P.; data curation, M.P.; writing-original draft preparation, M.P. and A.A.C.; writing-review and editing, M.P., A.A.C. and P.P.; supervision, P.P.; project administration, P.P.; funding acquisition, P.P. All authors have read and agreed to the published version of the manuscript.

Funding: This research received no external funding.

Institutional Review Board Statement: Not applicable.

Informed Consent Statement: Not applicable.

Data Availability Statement: Not applicable.

Conflicts of Interest: The authors declare no conflict of interest.

\section{References}

1. Lenucci, M.S.; De Caroli, M.; Marrese, P.P.; Iurlaro, A.; Rescio, L.; Böhm, V.; Dalessandro, G.; Piro, G. Enzyme-aided extraction of lycopene from high-pigment tomato cultivars by supercritical carbon dioxide. Food Chem. 2015, 170, 193-202. [CrossRef]

2. Szabo, K.; Emőke Teleky, B.; Ranga, F.; Simon, E.; Lelia Pop, O.; Babalau-Fuss, V.; Kapsalis, N.; Vodnar, D.C. Bioaccessibility of microencapsulated carotenoids, recovered from tomato processing industrial by-products, using in vitro digestion model. LWT 2021, 152, 112285. [CrossRef]

3. Roldán-Gutiérrez, J.M.; Dolores Luque de Castro, M. Lycopene: The need for better methods for characterization and determination. TrAC-Trends Anal. Chem. 2007, 26, 163-170. [CrossRef]

4. Grassino, A.N.; Ostojić, J.; Miletić, V.; Djaković, S.; Bosiljkov, T.; Zorić, Z.; Ježek, D.; Rimac Brnčić, S.; Brnčić, M. Application of high hydrostatic pressure and ultrasound-assisted extractions as a novel approach for pectin and polyphenols recovery from tomato peel waste. Innov. Food Sci. Emerg. Technol. 2020, 64, 102424. [CrossRef]

5. Lianfu, Z.; Zelong, L. Optimization and comparison of ultrasound/microwave assisted extraction (UMAE) and ultrasonic assisted extraction (UAE) of lycopene from tomatoes. Ultrason. Sonochem. 2008, 15, 731-737. [CrossRef] [PubMed] 
6. Luengo, E.; Condón-Abanto, S.; Condón, S.; Álvarez, I.; Raso, J. Improving the extraction of carotenoids from tomato waste by application of ultrasound under pressure. Sep. Purif. Technol. 2014, 136, 130-136. [CrossRef]

7. Eh, A.L.S.; Teoh, S.G. Novel modified ultrasonication technique for the extraction of lycopene from tomatoes. Ultrason. Sonochem. 2012, 19, 151-159. [CrossRef]

8. Rahimi, S.; Mikani, M. Lycopene green ultrasound-assisted extraction using edible oil accompany with response surface methodology (RSM) optimization performance: Application in tomato processing wastes. Microchem. J. 2019, 146, 1033-1042. [CrossRef]

9. Manzoor, M.F.; Zeng, X.; Rahaman, A.; Siddeeg, A.; Aadil, R.M.; Ahmed, Z.; Li, J.; Niu, D. Combined impact of pulsed electric field and ultrasound on bioactive compounds and FT-IR analysis of almond extract. J. Food Sci. Technol. 2019, 56, $2355-2364$. [CrossRef]

10. Cravotto, G.; Cintas, P. Power ultrasound in organic synthesis: Moving cavitational chemistry from academia to innovative and large-scale applications. Chem. Soc. Rev. 2006, 35, 180-196. [CrossRef]

11. Zia, S.; Khan, M.R.; Shabbir, M.A.; Aslam, A.; Kashif, M.; Khan, I.; Nadeem, M.; Ahmed, A.; Din, A.; Aadil, R.M. An inclusive overview of advanced thermal and nonthermal extraction techniques for bioactive compounds in food and food-related matrices. Food Rev. Int. 2020. [CrossRef]

12. Kumar, K.; Srivastav, S.; Sharanagat, V.S. Ultrasound assisted extraction (UAE) of bioactive compounds from fruit and vegetable processing by-products: A review. Ultrason. Sonochem. 2021, 70, 105325. [CrossRef] [PubMed]

13. Chemat, F.; Rombaut, N.; Meullemiestre, A.; Turk, M.; Perino, S.; Abert-vian, M. Review of green food processing techniques. Preservation, transformation, and extraction. Innov. Food Sci. Emerg. Technol. 2017, 41, 357-377. [CrossRef]

14. Chemat, F.; Vian, M.A.; Cravotto, G. Green extraction of natural products: Concept and principles. Int. J. Mol. Sci. 2012, 13, 8615-8627. [CrossRef]

15. Tekin, K.; Hao, N.; Karagoz, S.; Ragauskas, A.J. Ethanol: A promising green solvent for the deconstruction of lignocellulose. ChemSusChem 2018, 11, 3559-3575. [CrossRef] [PubMed]

16. Corrêa-Filho, L.C.; Lourenço, S.C.; Duarte, D.F.; Moldão-Martins, M.; Alves, V.D. Microencapsulation of tomato (Solanum lycopersicum L.) pomace ethanolic extract by spray drying: Optimization of process conditions. Appl. Sci. 2019, 9, 612. [CrossRef]

17. Zhang, L.; Zeng, X.; Fu, N.; Tang, X.; Sun, Y.; Lin, L. Maltodextrin: A consummate carrier for spray-drying of xylooligosaccharides. Food Res. Int. 2018, 106, 383-393. [CrossRef]

18. Nair, K.K.; Kharb, S.; Thompkinson, D.K. Inulin dietary fiber with functional and health attributes-A review inulin dietary fiber with functional and health attributes-A Review. Food Rev. Int. 2010, 26, 189-203. [CrossRef]

19. Svarovsky, L. Characterization of particles suspended in liquids. In Solid-Liquid Separation; Svarovsky, L., Ed.; ButterworthHeinemann: Oxford, UK, 2000; pp. 30-65; ISBN 0750645687.

20. Khuri, A.I.; Mukhopadhyay, S. Response surface methodology. Wiley Interdiscip. Rev. Comput. Stat. 2010, 2, 128-149. [CrossRef]

21. Amir, B.A.; Pougnet, P.; Hami, A. Embedded Mechatronics Systems 2, Analysis of Failures, Modeling, Simulation, and Optimization, 2nd ed.; Elsevier: Amsterdam, The Netherlands, 2020; pp. 157-187. [CrossRef]

22. Anguelova, T.; Warthesen, J. Lycopene stability in tomato powders. J. Food Sci. 2000, 65, 67-70. [CrossRef]

23. Re, R.; Pellegrini, N.; Proteggente, A.; Pannala, A.; Yang, M.; Rice-Evans, C. Antioxidant activity applying an improved abts radical cation decolorization assay. Free Radic. Biol. Med. 1999, 26, 1231-1237. [CrossRef]

24. Aliakbarian, B.; Palmieri, D.; Casazza, A.A.; Palombo, D.; Perego, P. Antioxidant activity and biological evaluation of olive pomace extract. Nat. Prod. Res. 2012, 26, 2280-2290. [CrossRef] [PubMed]

25. Del Castillo, E.; Montgomery, D.C.; McCarville, D.R. Modified desirability functions for multiple response optimization. J. Qual Technol. 1996, 28, 337-345. [CrossRef]

26. Costa, N.R.; Lourenço, J.; Pereira, Z.L. Desirability function approach: A review and performance evaluation in adverse conditions. Chemom. Intell. Lab. Syst. 2011, 107, 234-244. [CrossRef]

27. Derringer, G.; Suich, R. Simultaneous optimization of several response variables. J. Qual. Technol. 1980, 12, 214-219. [CrossRef]

28. Aguiar, J.; Estevinho, B.N.; Santos, L. Microencapsulation of natural antioxidants for food application-The specific case of coffee antioxidants-A review. Trends Food Sci. Technol. 2016, 58, 21-39. [CrossRef]

29. Mujumdar, A.S. Handbook of Industrial Drying, 3rd ed.; Mujumdar, A.S., Ed.; Taylor \& Francis: Boca Raton, FL, USA, 2006.

30. Robert, P.; Gorena, T.; Romero, N.; Sepulveda, E.; Chavez, J.; Saenz, C. Encapsulation of polyphenols and anthocyanins from pomegranate (Punica granatum) by spray drying. Int. J. Food Sci. Technol. 2010, 45, 1386-1394. [CrossRef]

31. Ahmed, M.; Akter, M.S.; Lee, J.C.; Eun, J.B. Encapsulation by spray drying of bioactive components, physicochemical and morphological properties from purple sweet potato. LWT_Food Sci. Technol. 2010, 43, 1307-1312. [CrossRef]

32. Lai, H.M.; Cheng, H.H. Properties of pregelatinized rice flour made by hot air or gum puffing. Int. J. Food Sci. Technol. 2004, 39, 201-212. [CrossRef]

33. Mangut, V.; Sabio, E.; Gañán, J.; González, J.F.; Ramiro, A.; González, C.M.; Román, S.; Al-Kassir, A. Thermogravimetric study of the pyrolysis of biomass residues from tomato processing industry. Fuel Process. Technol. 2006, 87, 109-115. [CrossRef]

34. Rossini, G.; Toscano, G.; Duca, D.; Corinaldesi, F.; Foppa Pedretti, E.; Riva, G. Analysis of the characteristics of the tomato manufacturing residues finalized to the energy recovery. Biomass Bioenergy 2013, 51, 177-182. [CrossRef]

35. Ruiz Celma, A.; Cuadros, F.; López-Rodríguez, F. Characterization of pellets from industrial tomato residues. Food Bioprod. Process. 2012, 90, 700-706. [CrossRef] 
36. Strati, I.F.; Oreopoulou, V. Effect of extraction parameters on the carotenoid recovery from tomato waste. Int. J. Food Sci. Technol. 2011, 46, 23-29. [CrossRef]

37. Priyadarsani, S.; Patel, A.S.; Kar, A.; Dash, S. Process optimization for the supercritical carbondioxide extraction of lycopene from ripe grapefruit (Citrus paradisi) endocarp. Sci. Rep. 2021, 11, 10273. [CrossRef] [PubMed]

38. Xi, J. Effect of High pressure processing on the extraction of lycopene in tomato paste waste. Chem. Eng. Technol. 2006, 29, 736-739. [CrossRef]

39. Kumcuoglu, S.; Yilmaz, T.; Tavman, S. Ultrasound assisted extraction of lycopene from tomato processing wastes. J. Food Sci. Technol. 2014, 51, 4102-4107. [CrossRef]

40. Grassino, A.N.; Pedisić, S.; Dragović-Uzelac, V.; Karlović, S.; Ježek, D.; Bosiljkov, T. Insight into high-hydrostatic pressure extraction of polyphenols from tomato peel waste. Plant Foods Hum. Nutr. 2020, 75, 427-433. [CrossRef]

41. Szabo, K.; Dulf, F.V.; Diaconeasa, Z.; Vodnar, D.C. Antimicrobial and antioxidant properties of tomato processing byproducts and their correlation with the biochemical composition. LWT 2019, 116, 108558. [CrossRef]

42. Ummat, V.; Tiwari, B.K.; Jaiswal, A.K.; Condon, K.; Garcia-Vaquero, M.; O’Doherty, J.; O'Donnell, C.; Rajauria, G. Optimisation of ultrasound frequency, extraction time and solvent for the recovery of polyphenols, phlorotannins and associated antioxidant activity from brown seaweeds. Mar. Drugs 2020, 18, 250. [CrossRef]

43. Ali, M.C.; Chen, J.; Zhang, H.; Li, Z.; Zhao, L.; Qiu, H. Effective extraction of flavonoids from Lycium barbarum L. fruits by deep eutectic solvents-based ultrasound-assisted extraction. Talanta 2019, 203, 16-22. [CrossRef]

44. Borrás-Enríquez, A.J.; Reyes-Ventura, E.; Villanueva-Rodríguez, S.J.; Moreno-Vilet, L. Effect of ultrasound-assisted extraction parameters on total polyphenols and its antioxidant activity from mango residues (Mangifera indica L. var. manililla). Separations 2021, 8, 94. [CrossRef]

45. Ferrari, P.F.; Pettinato, M.; Casazza, A.A.; De Negri, G.; Palombo, D.; Perego, P.; Pia, O. Polyphenols from Nerone Gold 26/6, a new pigmented rice, via non- conventional extractions: Antioxidant properties and biological validation. J. Chem. Technol. Biotechnol. 2021, 96, 1691-1699. [CrossRef]

46. Liao, J.; Zheng, N.; Qu, B. An Improved ultrasonic-assisted extraction method by optimizing the ultrasonic frequency for enhancing the extraction efficiency of lycopene from tomatoes. Food Anal. Methods 2016, 9, 2288-2298. [CrossRef]

47. Mao, Y.; Robinson, J.; Binner, E. Understanding heat and mass transfer processes during microwave- assisted and conventional solvent extraction. Chem. Eng. Sci. 2021, 233, 116418. [CrossRef]

48. Chemat, F.; Rombaut, N.; Sicaire, A.G.; Meullemiestre, A.; Fabiano-Tixier, A.-S.; Abert-Vian, M. Ultrasound assisted extraction of food and natural products. Mechanisms, techniques, combinations, protocols and applications. A review. Ultrason. Sonochem. 2017, 34, 540-560. [CrossRef]

49. Oliveira, V.S.; Rodrigues, S.; Fernandes, F.A.N. Effect of high power low frequency ultrasound processing on the stability of lycopene. Ultrason. Sonochem. 2015, 27, 586-591. [CrossRef] [PubMed]

50. Deng, Y.; Zhao, S.; Yang, X.; Hou, F.; Fan, L.; Wang, W.; Xu, E.; Cheng, H.; Guo, M.; Liu, D. Evaluation of extraction technologies of lycopene: Hindrance of extraction, effects on isomerization and comparative analysis-A review. Trends Food Sci. Technol. 2021, 115, 285-296. [CrossRef]

51. Goula, A.M.; Ververi, M.; Adamopoulou, A.; Kaderides, K. Green ultrasound-assisted extraction of carotenoids from pomegranate wastes using vegetable oils. Ultrason. Sonochem. 2017, 34, 821-830. [CrossRef] [PubMed]

52. Preece, K.E.; Hooshyar, N.; Krijgsman, A.J.; Fryer, P.J.; Zuidam, N.J. Pilot-scale ultrasound-assisted extraction of protein from soybean processing materials shows it is not recommended for industrial usage. J. Food Eng. 2017, 206, 1-12. [CrossRef]

53. Kulkarni, V.M.; Rathod, V.K. Mapping of an ultrasonic bath for ultrasound assisted extraction of mangiferin from Mangifera indica leaves. Ultrason. Sonochem. 2014, 21, 606-611. [CrossRef]

54. Eun, J.; Maruf, A.; Das, P.R.; Nam, S. A review of encapsulation of carotenoids using spray drying and freeze drying A review of encapsulation of carotenoids using spray drying and freeze drying. Crit. Rev. Food Sci. Nutr. 2019, 60, 3547-3572. [CrossRef] [PubMed]

55. De Barros Fernandes, R.V.; Borges, S.V.; Botrel, D.A. Gum arabic/starch/maltodextrin/inulin as wall materials on the microencapsulation of rosemary essential oil. Carbohydr. Polym. 2014, 101, 524-532. [CrossRef]

56. Pettinato, M.; Aliakbarian, B.; Casazza, A.A.A.; Perego, P. Encapsulation of antioxidants from spent coffee ground extracts by spray drying. Chem. Eng. Trans. 2017, 57, 1219-1224. [CrossRef]

57. Nishad, J.; Mir, S.A.; Walia, K. Optimization of spray drying technology for sugarcane juice using natural and synthetic encapsulating agents. Sugar Tech 2019, 21, 749-755. [CrossRef]

58. Ma, W.; Zhang, J.; Shu, L.; Tan, X.; An, Y.; Yang, X.; Wang, D.; Gao, Q. Optimization of spray drying conditions for the green manufacture of $\gamma$-aminobutyric acid-rich powder from Lactobacillus brevis fermentation broth. Biochem. Eng. J. 2020, 156, 107499. [CrossRef]

59. Chasekioglou, A.N.; Goula, A.M.; Adamopoulos, K.G.; Lazarides, H.N. An approach to turn olive mill wastewater into a valuable food by-product based on spray drying in dehumidified air using drying aids. Powder Technol. 2017, 311, 376-389. [CrossRef]

60. Shu, B.; Yu, W.; Zhao, Y.; Liu, X. Study on microencapsulation of lycopene by spray-drying. J. Food Eng. 2006, 76, 664-669. [CrossRef]

61. Souza, A.L.R.; Hidalgo-Chávez, D.W.; Pontes, S.M.; Gomes, F.S.; Cabral, L.M.C.; Tonon, R.V. Microencapsulation by spray drying of a lycopene-rich tomato concentrate: Characterization and stability. LWT_Food Sci. Technol. 2018, 91, 286-292. [CrossRef] 
62. Mahdi, S.; Ghalegi, M.; Dehnad, D. Influence of spray drying on water solubility index, apparent density, and anthocyanin content of pomegranate juice powder. Powder Technol. 2017, 311, 59-65. [CrossRef]

63. Yousf, N.; Nazir, F.; Salim, R.; Ahsan, H.; Sirwal, A. Water solubility index and water absorption index of extruded product from rice and carrot blend. J. Pharmacogn. Phytochem. 2017, 6, 2165-2168. 